\title{
Proses Penyelesaian Kredit Bermasalah Pada PT. BPD Sumatera Barat Cabang Pasar Raya Padang
}

\author{
Anisa Asyari 1), Doni Marlius ${ }^{2)}$ \\ 1.2) Akademi Keuangan dan Perbankan Padang \\ Anisaasyari88@gmail.com
}

\begin{abstract}
The purpose of this study was to determine the process of non-performing loans at PT. BPD Sumatera Barat Cabang Pasar Raya Padang. The research method used is descriptive research method. The result of the research is where the NonPerforming Loans Settlement Process of PT. BPD Sumatra Barat Cabang Pasar Raya Padang, namely by rescheduling, reconditioning, restructuring and processes such as conducting early warnings, collections, credit restructuring, granting relief from payment of interest arrears and fines, handing over nonperforming loans to third parties, organizing non-performing loans settlement through collateral auctions or confiscate the guarantee.
\end{abstract}

\section{Keywords: Non-Performing Credit}

\section{PENDAHULUAN}

Perbankan dalam penyaluran kredit sangat ketat penyelenggaraanya, mengingat situasi ekonomi yang banyak mengalami penurunan, dan juga penyaluran kredit saat ini agak sedikit susah dibandingkan sebelum pandemi karena bank sangat berhati hati agar tidak merusak kegiatan perbankan lainnya. Jika kegiatan kredit terganggu maka akan berdampak pada kegiatan perbankan lainnya.

Menurut Undang Undang No 10 tahun 1998 "Kredit ialah penyediaan uang atau tagihan yang dipersamakan dengan itu berdasarkan persetujuan dan kesepakatan pinjam meminjam antara bank dengan pihak peminjam dana dengan ketentuan melunasi hutangnya dengan jangka waktu yang disepakati beserta bunga".

Bank sangat berguna untuk menunjang kelancaran perekonomian yaitu untuk penyedia modal dalam bentuk kredit karena jumlah yang disalurkan menentukan keuntungan yang akan di peroleh bank. Kredit adalah salah satu kegiatan bisnis bank yang mengandung resiko yang besar di bandingkan dengan kegiatan perbankan lainnya (Rosmilia, 2009). Kredit sangat dinutuhkan bagi masyarakat yang membutuhkan dana agar bisa mengembangkan usaha rakyat, dimana kredit digunakan untuk penambahan modal usaha Tanjung, (2019). 
Berikut ini perkembangan Kresit Produktif dan Konsumtif yang terjadi pada PT. BPD Cabang Pasar Raya Padang tiga tahun terakhir dapat dilihat pada tabel di bawah ini :

\section{Tabel 1 \\ Kolektibiliti}

PT. BPD Sumatera Barat Cabang Pasar Raya Padang (dalam jutaan rupiah)

\begin{tabular}{cccc}
\hline Kolektibiliti & $\mathbf{2 0 1 8}$ & Nilai Wajar & $\mathbf{2 0 1 9}$ \\
\hline Lancar & 955.339 & 1.036 .932 & 1.013 .789 \\
Dalam perhatian & 18.160 & 26.446 & 10.289 \\
khusus & 2.184 & 1.727 & 1.961 \\
Kurang lancer & 4.140 & 4.281 & 1.503 \\
Diragukan & 21.849 & 28.565 & 34.076 \\
Macet & 2,7 & 3,1 & 3,5 \\
NPL &
\end{tabular}

Sumber : PT. BPD Sumatera Barat Cabang Pasar Raya Padang

Berdasarkan Tabel 1 terlihat bahwa jumlah kredit macet sangat tinggi jumlahnya dibandingkan dengan jenis yang lain dimana pada tahun 2018 jumlahnya Rp. 21.849.000.000 tahun 2019 Rp. 28.565.000.000 tahun $2020 \mathrm{Rp}$. 34.076.000.000. yaitu mengalami kenaikan setiap tahunnnya.

Kredit bermasalah merupakan kredit yang telah jatuh tempo tidak dapat dilunasi oleh debitur sebagaimana mestinya sesuai dengan perjanjian Widayati \& Herman, (2019). Mencari penyebab terjadinya kredit bermasalah sangat rumit disebabkan banyak faktor yang mempengaruhi baik yang bersifat internal maupun eksternal. Faktor eksternal (dari luar perusahaan) seperti keadaan ekonomi, persaingan, bencana alam, dan dari debitur itu sendiri. sedangkan faktor internal (dari pihak bank) seperti kurangnya penilaian yang matang dalam pemberian kredit atau minimnya pengawasan dan pembinaan terhadap kredit yang di berikan. Kredit bermasalah disebabkan oleh beberapa faktor yang berkaitan satu dengan lainnya, maka harus segara mendapatkan penyelesaian agar tidak terganggunya kegiatan dan kondisi bank.

Berdasarkan latar belakang diatas, maka rumusan masalah dalam penelitian ini ialah bagaimana cara penyelesaian kredit bermasalah pada PT. BPD Sumatera Barat Cabang Pasar Raya Padang?

\section{METODE PENELITIAN}

Didalam melaksanakan penelitian menggunakan metode- metode pengumpulan data sebagai berikut :

\section{Metode Pengumpulan Data}

1. Studi Pustaka (Library Research)

Penelitian ke perpustakaan library research adalah penelitian keperpustakaan, mencari landasan teori melalui buku buku bacaan, literatur, bahan - bahan kuliah serta artikel - artikel yang berhubungan dengan topik pembahasan. 


\section{Studi Lapangan (Field Research)}

Penelitian yang langsung dilakukan ke lapangan, yajtu dengan melakukan penelitian ke PT. BPD Sumatera Barat Cabang Pasar Raya Padang dengan melakukan permintaan data dan wawancara serta tanya jawab agar mendapatkan keterangan yang berkaitan dengan penulisan ini.

\section{Metode Analisa}

Saat menganalisa data, penulisan menggunakan metode deskriptif yaitu dengan mengutraikan secara sistematis dari fakta - fakta yang didapat kemudian dihubungkan dengan proses penyeesaian kredit bermasalah pada PT. BPD Sumatera Barat Cabang Pasar Raya Padang.

\section{HASIL DAN PEMBAHASAN Pengertian Bank}

Menurut Undang - Undang RI No 10 tahun 1998 tentang perbankan, Bank yaitu badan usaha yang menghimpun dana dari masyarakat dalam bentuk simpanan dan menyalurkan kembali dalam bentuk kredit dengan tujjuan untuk meningkatkan taraf hidup masyarakat banyak.

Menurut Pratama \& fernos, (2019) Bank adalah lembaga keuangan yang ada di Indonesia yang mempunyai peran penting bagi kelangsungan perekonomian Indonesia, bank merupakan lembaga keuangan yang kegiatan utamanya ialah menghimpun dana dari masyarakat dan disalurkan kembali dalam bentuk kredit dan lainnya.

\section{Pengertian Kredit}

Pengertian kredit menurut (Widayati \& Herman, 2019) Kredit berasal dari bahasa latin yaitu "credere” yang berarti kepercayaan. Kredit dan kepercayaan ialah suatu kesatuan yang tak bisa dipisahkan.

Menurut Drs. Thomas Suyatno, (1995) kredit yaitu kepercayaan, dimana dasar dari kredit adalah kepercayaan. Maksudnya kreditur percaya kepada debitur bahwa akan dikembalikan kredit yang diberikan sesuai dengan perjanjian.

Menurut Riyadi, (2009) krediy yaitu suatu sebuah prestasi bank dalam memberikan uang dan barang dengan memperoleh balasan dari prestasi yang diemui pada waktu yang akan datang.

Kredit merupakan salah satu fungsi bank yang bisa meringankan permasalahan masyarakat umum untuk memenuhi kebutuhan hidupnya.

\section{Jenis - Jenis Kredit}

Menurut Kasmir, (2014) kredit terbagi dalam 5 jenis yaitu :

1. Dilihat dari segi agunan

a. Kredit Investasi

Kredit yang diberikan untuk investasi, misalnya membangun pabrik, rumah, pembelian mesin-mesin, tanah, dan lainnya.

b. Kredit Modal Kerja

Kredit yang disalurkan untuk keperluan kegiatan modal kerja seperti membeli bahan baku, peralatan uaha dan lain - lain 
2. Dilihat dari segi tujuan

a. Kredit Produktif

Kredit yang disalurkan untuk kegiatan produksi barang ataupun jasa seperti kredit yang diberikan kepada pabrik, industri, pertanian.

b. Kredit Komsumtif

Kredit yang diberikan kepada pribadi atau dipakai (dikimsumsi) sendiri, seperti membeli rumah untuk keperluan pribadi.

c. Kredit Perdagangan

Kredit yang diberikan kepada para pedagang digunakan untuk menambah modal usaha dagang yang pembayarannya diharapkan dari hasil penjualan barang dagang.

3. Dilihat dari jangka waktu

a. Kredit jangka pendek

Kredit yang mempunyai jangka waktu maksimal 1 tahun atau kurang dari 1 tahun, biasanya untuk modal kerja. Contohnya untuk pertanian menanam padi.

b. Kredit jangka menengah

Kredit yang jangka waktunya 1 s/d 3 tahun, biasanya untuk investasi.

c. Kredit jangka panjang

Kredit yang jangka waktunya lebih dari tiga tahun, biasanya digunakan untuk investasi jangka panjang.

4. Dilihat dari segi jaminan

a. Kredit jaminan

Kredit yang diberikan dengan suatu jaminan, dimana jaminan itu bisa berupa barang berwujud atau tidak, nilai kredit yang akan diberikan sesuai dengan jaminan yang diberikan.

b. Kredit tanpa jaminan

Kredit yang disalurkan tanpa jaminan barang, tetapi dilihat ada kemampuan bayar dari nasabah seperti pegawai tetap yang menghasilkan penghasilan tetap

5. Dilhat dari sektor usaha

a. Kredit Sektor Pertanian

kredit yang diberikan untuk kegiatan pertanian dan perkebunan masyarakat.

b. Kredit Sektor Industri

Adalah kredit yang disalurkan kepada industri, baik industri besar, kecil, dan menengah.

c. Kredit Sektor Profesi

Yaitu kredit yang disalurkan kepada professional seperti guru, dokter, pengacara dan lainnya. 


\section{Tujuan dan Fungsi Kredit}

\section{Tujuan Kredit}

Menurut (Fahmi, 2014) tujuan pemberian kredit yaitu :

1. Mencari Keuntungan

Menambah keuntungan dari hasil penyaluran kredit yang diberikan hasil yang diterima dalam bentuk bunga dan biaya administrasi kredit.

2. Membantu usaha nasabah

Dapat membantu usaha nasabah yang membutuhkan dana baik untuk modal kerja ataupun investasi bisnis.

3. Membantu pemerintah

Yaitu membantu pemerintah untuk menaikkan taraf hidup asyarakat, dimana dengan adanya kredit masyarakat mampu untuk mengembangkan usahanya.

\section{Fungsi Kredit}

Fungsi Kredit menurut (Amelia \& Marlius, 2018) adalah sebagai berikut :

1. Untuk meningkatkan daya guna uang

Dengan adanya kredit maka bisa meningkatkan daya guna uang untuk kegiatan usaha

2. Untuk meningkatkan peredaran dan lalu lintas uang

3. Sebagai alat stabilitas ekonomi

Dengan adanya kredit yang diberikan bisa menambah jumlah barang yang dibutuhkan oleh masyarakat.

4. Untuk meningkatkan gairah berusaha

Agar pebisnis lebih semangat dalam menjalankan usahanya yaitu dengan kredit bisa menambah modal usahanya

5. Untuk meningkatkan hubungan internasional

6. Untuk meningkatkan pemerataan pendapat

Jika banyak kredit yang disalurkan, maka semakin baik yaitu bisa meningkatkan pendapatan, karena jika kredit yang disalurkan untuk membangun pabrik maka membutuhkan tenaga kerja sehingga bisa menurunkan pengguran.

\section{Prinsip Pemberian Kredit}

Menurut (yubita, 2018) adapun prinsip pemberian kredit yaitu :

1. Dengan Prinsip 5C
a. Character (Sifat / watak )
b. Capacity ( Kemampuan )
c. Capital (Modal)
d. Conditional (Kondisi / keadaan)
e. Collateral (Agunan / Jaminan)

2. Dengan Prinsip 7P yaitu sebagai berikut :
a. Personality
b. Purpose
c. Party
d. Payment
e. Prospect
f. Profitability 


\section{g. Protection}

\section{Unsur - Unsur Dalam Pemberian Kredit}

Menurut Widayati \& Maiwati, (2019) unsur - unsur dalam pemberian kredit adalah :

1. Kepercayaan

Dimanan kreditur percaya bajawa debitur akan mengembalikan pinjaman kreditnya kembali sesuai perjanjian.

2. Kesepakatan

Harus ada kesepakatan antara kreditur dan debitur karena dalam kesepakatan akan dituangkan suatu perjanjian yang harus disepakati kedua belah pihak dan ditandatangani.

3. Jangka Waktu

Jangka waktu yang diberikan untuk mengembalikan kembali kredit sesuai dengan kesepakatan antara debitur dan kreditur.

4. Resiko

Setiap kredit pasti memiliki resiko baik itu resiko yang disengaja oleh nasabah yang lalai ataupun tidak disengaja seperti terjadi bencana alam, maka pihak bank harus bisa mencari solusi untuk menekan resiko yang akan terjadi.

5. Prestasi

Prestasi yang dimiliki kreditur untuk pemberian kepada debitur.

\section{Kriteria Kredit}

Agar dapat melihat aktiva produktif bank sejauh mana kredit bermasalah terdapat pada bank tersebut dinilai dari kolektibilitas kredit. Kolektibilitas kredit adalah keaadaan pembayaran pokok, angsuran pokok, dan bunga kredit oleh nasabah dan tingkat kemungkinan diterima kembali dana yang diberikan. Dengan melihat kolektibilitas kredit kita dapat menilai kualitas kredit yang diberikan. (Widayati \& Herman, 2019)

Kolektibilitas kredit berdasarkan ketentuan Bank Indonesia adalah sebagai berikut :

1. Kredit Lancar

Kredit lancar yaitu kredit tidak mengalami kendala dalam pengembalian pokok dan bunga pinjaman.

2. Kredit dalam perhatian khusus

Kredit dalam perhatian khusus yaitu kredit yang memiliki tunggakan pokok atau bunga mengalami penundaan selama $1 \mathrm{~s} / \mathrm{d} 90$ hari.

3. Kredit kurang lancar

Kredit kurang lacar yaitu kredit yang pengembalian pokok pinjaman serta bunga telah mengalami penundaan selama 91 s/d 180 hari.

4. Kredit diragukan

Kredit diragukan yaitu kredit yang pengembalian pokok pinjaman dan bunganya telah mengalami penundaan selama 181 s/d 270 hari.

5. Kredit macet

Kredit macet yaitu kredit yang pengembalian pokok pinjaman dan bunganya telah mengalami penundaan lebih dari satu tahun sejak jatuh tempo yang telah ditentukan. 


\section{Pengertian Kredit Bermasalah}

Menurut Widayati, (2019) kredit bermasalah yaitu kredit yang sejak jatuh tempo tidak dapat dilunasi oleh debitur sebagaimana mestinya sesuai perjanjian yang telah disepakati.

\section{Tindakan Penyelamatan Kredit}

Jika bank memutuskan untuk melakukan tindakan penyelamatan kredit bermasalah maka itu terjadi pada kesulitan yang dihadapi oleh nasabah, maka tindakan yang di ambil ada empat cara yaitu :

1. Rescedulling

Penjadwalan kembali tentang pembayaran kewajiban debitur contohnya memperpanjang jangka waktu kredit dari 6 bulan menjadi 1 tahun, memperpanjang jangka waktu angsuran dari 30 kali menjadi 42 kali.

2. Reconditioning

Pihak bank melakukan tindakan mengubah sebagian atau seluruh kondisi persyaratan yang disepakati semula bersama debitur dan dituangkan dalam perjanjian kredit.

3. Restructuring

Penyelamatan kredit dengan cara mengubah komposisi pembiayaan yang mendasari pemberian kredit, meliputi :

a. Penambahan Dana oleh Bank

b. Konversi seluruh atau sebagian tungggakan bunga menjadi pokok kredit baru

c. Penjadwalan kembali.

4. Penyitaan jaminan

Penyitaaan jaminan yaitu jalan terakhir apabila nasabah tidak sanggup dalam membayar kewajibannya dan tidak ada itikad baik dari nasabah untuk membayar kewajibannya.

\section{Prosedur Pemberian Kredit}

\section{Permohonan Kredit}

Berdasarkan pelaksanaan pemberian kredit Pada PT BPD Sumatera Barat Cabang Pasar Raya Padang dimualai dari penerimaan permohonan kredit yang diajukan calon debitur. Permohonan kredit diajukan dalam bemtuk tertulis dengan mengisi format yang telah disediakan oleh pihak bank BPD Sumatera Barat Cabang Pasar Raya Padang.

Dalam menilai permohonan kredit yang diajukan, PT BPD Sumatera Barat Cabang Pasar Raya Padang memiliki kriteria calon debitur sebagai berikut :

a. Warga Indonesia yang cakap hukum (usia minimal 21 tahun)

b. Mempunyai penghasilan yang jelas dan tetap yang bisa diyakini oleh pihak PT. BPD Sumatera Barat Cabang Pasar Raya Padang.

c. Tidak tercatat daftar hitam (black list) yang terdaftar pada Bank Indonesia

PT BPD Sumatera Barat Cabang Pasar Raya Padang memberikan persyaratan yang harus dipenuhi dan dilsmpirkan oleh calon debitur dalam permohonan kredit yaitu : 

a. Fotocopy KK dan KTP
b. Pas foto
c. Foto copy perizinan usaha
d. NPWP
e. SIUP
f. SITU
g. TDP
h. Foto copy jaminan (serifikat rumah / tanah, BPKB, Surat Lainnya )
i. Data - data keuangan
j. Dokumen pendukung

2. Cek Kelengkapan Data

Pemeriksaan yang dilaukan oleh pihak bank merupakan bentuk dalam pemberian kredit, karena dari hasil pemeriksaan kelengkapan serta keaslian data - data tersebut bank akan menilai karakter calon debitur. Karakter adalah salah satu bentuk dari prinsip pemberian kredit 5C diantaranya character, capacity, capital, collateral, condition of economi.

\section{BI Checking}

Setelah melakukan pemeriksaan kelengkapan dokumen, selanjutnya yaitu memeriksa riwayat kredit calon debitur pada bank lain dengan menggunakan SID (Sistem Informasi Debitur) yang disebut dengan BI Cheking. Pemeriksaan SID adalah salah satu tindakan untuk kehati - hatian pihak bank dalam pemberian kredit, agar mengurangi resiko kredit bermasalah. Hasil dari pemeriksaan SID pihak bank bisa mengetahui Capacity calon debitur, sebab hasil dari BI Checking akan terlihat data pinjaman nasabah pada bank lain, jadi pihak bank bisa menilai kemampuan calon debitur.

\section{Cek Agunan Usaha}

Proses selanjutnya yaitu melakukan pengecekan agunan usaha debitur, tujuannya agar mengetahui modal yang dimiliki calon debitur. Serta menilai apakah degan modal yang dimiliki bisa mengembalikan kembali kredit sesuai dengan perjanjian.

\section{Penilaian Agunan Usaha}

Selanjutnya yaitu pihak bank menilai Agunan usaha calon debitur, baik dari segi keaslian yang dijaminkan, serta keabsahannya.

\section{Rekomendasi}

Apabila hasil analisis kredit kredit yang dilakukan oleh devisi kredit sesuai dengan ketentuan PT. BPD Sumatera Barat Cabang Pasar Raya maka devisi kredit mengajukan rekomendasi kepada Pimpinan Cabang Pasar Raya untuk merekomendasikan kredit tersebut.

\section{Keputusan Kredit}

Dari hasil rekokmendasi kredit maka pihak bank akan memberikan keputusan kredit apakah diterima atau tidak.

\section{Penandatangan Perjanjian Kredit}

Setelah kredit diterima, kedua belah pihak membuat perjanjian kredit dan menandatangani akad kredit, lalu pihak bank mengikat jaminan. 


\section{Realisasi Kredit}

Selanjutnya kredit akan direalisasikan dengan syarat membuka rekening tabungan PT. BPD Sumatera Barat Cabang Pasar Raya Padang. Kredit disalurkan melalui tabungan nasabah.

Jadi dalam pemberian kredit pada PT. BPD Sumatera Barat Cabang Pasar Raya Padang yaitu dimulai dari permohonan kredit sampai dengan realisasi kredit, tetapi setelah kredit disalurkan dengan menggunakan pengawasan kredit yang tujuannya membangun kedisiplinan debitur untuk membayar pinjamannya dengan tepat waktu.

\section{Kredit Bermasalah Dan Penyelesaiannya}

\section{Kredit Bermasalah}

Secara umum dalam pemberian kredit banyak menghadapi kendala, baik itu hambatan intern ataupun ekstern yang menimbulkan kredit bermasalah. Hambatan intern adalah hambatan yang timbul dari pihak bank seperti :

a. Kurang menilai latar belakang calon debitur

b. Kurang paham dalam menganalisis maksud dan tujuan penggunaan kredit dan sumber pemabayaran kembali.

c. Kurang pemahaman atas kebutuhan keuangan yang sebenarnya dari calon debitur

d. Kurang mahir dalam menganalisis laporan keungan calon debitur.

e. Kurang pengalaman pejabat kredit

f. Banyak memberikan kelonggaran

g. Pejabat kredit mudah dipengaruhi calon debitur

Hambatan dari pihak ekstern yaitu yang timbul dari nasabah :

a. Menurunnya perekonomian debitur

b. Kegiatan usaha debitur yang mulai menurun

c. Penurunan omset debitur

d. Usaha debitur tutup

\section{Penyelesaiaan Kredit Bermasalah}

Dalam hal ini PT. BPD Sumatera barat Cabang Pasar Raya Padang menempuh langkah penyelesaian kredit bermasalah adalah sebagai berikut :

a. Melakukan peringatan dini

Pihak Bank BPD mengirimkan surat peringatan dini kepada nasabah yang mengalami tunggakan kredit atau sudah tidak lancar lagi dalam pembayaran kreditnya, untuk segera membayar tunggakan kredit yang telah terjadi.

b. Penagihan

Petugas kredit Bank BPD melakukan penagihan kredit kepada nasabah yang mengalami penungggakan kredit, penagihan tidak saja dibatasi kepada debitur, tetapi juga dilakukan kepada suami atau istri debitur serta penjamin atau pihak yang terkait dalam penandatanganan kredit. 
c. Restrukturisasi kredit

Petugas kredit Bank BPD melakukan usaha restrukturisasi kredit dengan cara penurunan suku bunga, melakukan perpanjangan jangka waktu kredit.

d. Pemberian keringanan pembayaran tunggakan bunga dan denda

Pemberian keringanan pemabayaran bunga untuk menyelesaikan kredit dengan kolektibilitas diragukan dan macet dengan cara pemabayaran secara lunas ataupun secara angsuran.

e. Penyerahan kredit bermasalah pada pihak ketiga

1. Melalui Pihak Kejaksaan

2. Melalui Pengadilan Negeri

3. Melalui Lelang Pemerintah

f. Pelelangan Agunan atau jaminan

Tindakan Terakhir dari proses penyelesaian kredit bermasalah jika semua cara telah ditempuh tetapi debitur tidak mempunyai itikad baik maka pihak PT. BPD Sumatera Barat Cabang Pasar Raya Padang akan melakukan pelelangan agunan atau jaminan yang diberikan debitur.

\section{SIMPULAN}

Berdasarkan uraian diatas, maka dapat disimpulkan sebagai berikut :

1. Prosedur pemberian kredit pada pada PT. BPD Sumatera Barat Cabang Pasar Raya Padang dilakukan mulai dari pengajuan permohona kredit sampai ke realisasi kredit, kemudian dilakukan pengawasan kredit untuk meningkatkan kedisiplinan debitur untuk melunasi pinjamannya

2. Kredit bermasalah pada PT. BPD Sumatera Barat Cabang Pasar Raya Padang disebabkan oleh pendapatan debitur yang menurun akibat pandemi covid 19 karena debitur terbatas dalam menjalankan kegiatan usahanya, sehingga kemampuan membayar angsuran pokok dan bunga pinjaman nasabah mengalami masalah, sehingga kredit menjadi tidak lacar.

3. Upaya yang dilakukan oleh PT. BPD Sumatera Barat Cabang Pasar Raya Padang untuk mengatasi kredit bermasalah adalah sebagai berikut :

a. Melakukan peringatan dini

b. Penagihan

c. Rektrukturisasi kredit

d. Pemberian keringanan pembayaran tungggakan bunga dan denda

e. Penyerahan kredit bermasalah pada pihak ketiga

f. Melakukan pelelangan agunan

\section{UCAPAN TERIMA KASIH}

Dengan menyebut nama Allah SWT yang Maha Pengasih lagi Maha Penyayang, penulis ucapkan puji dan syukur atas Kehadirat-Nya, yang telah melimpahkan Rahmat, hidayah-Nya kepada saya. Penulis ingin menyampaikan terimakasih kepada pimpinan PT. BPD Sumatera Barat Cabang Pasar Raya Padang serta semua pihak yang telah membantu. Akhir kata penulis ucapkan 
terimakasih, semoga apa yang penulis tuangkan dalam karya kecil ini memberikan manfaat terutama bagi saya sendiri selaku penulis. Amin ya Rabbal'Alamin

\section{DAFTAR PUSTAKA}

Alanshari, F., \& Marlius, D. (2018). Prosedur Pemberian Kredit KPR Pada PT. Bank Tabungan Negara (Persero) TBK Cabang Pembantu Bukittinggi. https://doi.org/10.31227/osf.io/rsfhc

Amelia, L., \& Marlius, D. (2018). Pengendalian Kredit Dalam Upaya Menciptakan Bank Yang Sehat Pada PT. Bank Pembangunan Daerah Sumatera Barat Cabang Utama Padang. 2007, 1-11. https://doi.org/10.31227/osf.io/kpc64

Thomas Suyatno. (1995). Dasar-dasar perkreditan. Gramedia Pustaka Utama, Jakarta,

Fahmi, I. (2014). Manajemen Perkreditan. Bandung: Alfabeta.

Ikbal, M., \& Marlius, D. (2017). Pengaruh Jumlah Taksiran Dan Uang Pinjaman Terhadap Laba Bersih Pada PT. Pegadaian (UPC) Gurun Laweh. https://doi.org/10.31227/osf.io/uch4a

Kasmir. (2014). Bank dan Lembaga keuangan lainnya. Jakarta: Raja Grafindo Persada.

Pratama, D., \& fernos, jhon. (2019). Prosedur Pelaksanaan Kredit Usaha Rakyat (Kur) Pada Pt. Bank Nagari Cabang Padang. https://doi.org/10.31227/osf.io/ag68j

Riyadi, D. (2009). Tindakan Penyelamatan Dan Penyelesaian Kredit Bermasalah Di PT. Bank Danamon Indonesia Tbk. Cabang semarang pemuda. 1, 1-133.

Rosmilia, R. (2009). Pelaksanaan Penyelesaian Kredit Bermasalah. Tesis, Magster Kenotariatan Universitas Diponegoro Semarang.

Shanjaya, A. R., \& Marlius, D. (2017). Peranan Laporan Keuangan Dalam Kebijaksanaan Pemberian Kredit Kepada Calon Nasabah Pada PT. BPR Batang Kapas. https://doi.org/10.31227/osf.io/uxmg6

Tanjung, M. S. (2019). Penyelesaian Kredit Bermasalah Pada PT. Bank Perkreditan Rakyat (Bpr) Mitra Danagung Padang. 1-20. https://doi.org/10.31219/osf.io/3wa5q

Widayati, R. (2019). Upaya Penanganan Kredit Bermasalah Pada Bank Nagari Cabang Utama Padang. Akademi Keuangan Dan Perbankan, 1-12. https://doi.org/10.31219/osf.io/ewm65

Widayati, R., \& Herman, U. (2019). Penyelesaian Kredit Bermasalah Pada PT. Bank Perkreditan Rakyat (Bpr) Nagari Kasang. 1-14. https://doi.org/10.31219/osf.io/d738z

Widayati, R., \& Maiwati, S. (2019). Aktivitas Pemberian Kredit Komersil Pada Bank Nagari Cabang Sijunjung. 1-12. https://doi.org/10.31219/osf.io/fnxaj

Yubita, Tanjung, M. S.(2018). Proses Penyelesaian Kredit Bermasalah. 7, 1-12. 